\title{
Prophylaxis of Trachoma
}

The Ophthalmological Society of Egypt in 1920 elected a Committee to study and report on the means of prophylaxis against trachoma and acute ophthalmias. This report has just been published in the Annual Bulletin of the Society. It is a serious effort to grapple with a condition of affairs as old as the Pharaohs and affecting a proportion of the population of native Egyptians which has been estimated to be about 90 per cent. From a study of the published Annual Reports of the Director of Ophthalmic Hospitals since 1912, it is clear that not only has there been an improvement in the incidence of trachoma and acute ophthalmias, but that by the agency of the Ophthalmic Hospitals, now twenty in number, a firm desire has been implanted in the minds of the educated population to proceed still further in the direction of universal facilities for ophthalmic treatment and adequate means of prophylaxis. So that the Ophthalmological Society's report should be considered rather as a response to a popular feeling than as a new trumpet call to modern ideas of health.

The English and the arrangement of the report are defective, but are nevertheless highly creditable to a body of ophthalmic surgeons, the native language of the majority of whom is Arabic.

A good many of the suggestions are such as will be found in the usual treatises on diseases of the eye, others are taken without acknowledgment from MacCallan's book, "Trachoma in Egypt." We are not in a position to give an opinion on the general sanitary measures recommended, nor on the advisability of introducing Universal Elementary Education for boys and girls, though they seem to be a sound foundation for the improvement of any generally illiterate people who, outside some of the largest towns, are unacquainted with even the rudiments of sanitary science.

\section{MERCHANT SHIPPING. STANDARD OF REJECTION FOR COLOUR-BLINDNESS IN SEAMEN}

\section{Report to the Board of Trade by Dr. Edridge-Green}

\author{
Consultative Branch, \\ Mercantile Marine Department, \\ BOARD OF TRADE, \\ 68 , Victoria Street, \\ LONDON, S.W.1, \\ November 7th, 1921.
}

Sir,- - I beg to enclose my report on the proposed Standard of Rejection for Colour-blindness for Seamen. 